

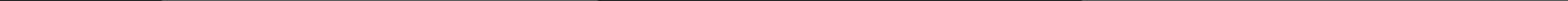




\section{Asimetrías en la protección de la forma de vida campesina colombiana. Hacia una protección especial de la forma de vida campesina*}

Por María José Hernández Castaño ${ }^{1}$

\section{Introducción}

Este artículo busca evidenciar la deuda que Colombia tiene con la protección de la forma de vida campesina en su proclamación como estado pluriétnico y multicultural a través de la Constitución de 1991.

Inicialmente, se describe el surgimiento y consolidación del movimiento campesino, haciendo especial énfasis en el giro de identificación étnica como estrategia para hacer frente a la represión sufrida por aquel, lo que desembocaría en la división de un movimiento social conformado por personas que en realidad poseían primigeniamente objetivos políticos similares.

* $\quad$ Artículo recibido en septiembre de 2015

Artículo aprobado en octubre de 2015

Abogada de la Universidad Javeriana, candidata a magíster en derecho administrativo de la Universidad Externado de Colombia. Participó en la clínica jurídica en Derecho y Territorio de la Universidad Javeriana en la defensa de comunidades vulnerables. Se desempeñó como asistente de investigación para la capacitación en el sistema probatorio de la Ley 1448 de 2011 de los jueces de tierras por parte de la Escuela Judicial Rodrigo Lara Bonilla y como asesora en la Unidad Nacional de Protección en la atención de víctimas y desmovilizados. Actualmente trabaja en un despacho particular.

Correo electrónico: mariajosehdez88@gmail.com 
Posteriormente, se revisan las demandas y la participación de estos movimientos sociales en la Asamblea Nacional Constituyente de 1991. Igualmente, se realiza un análisis de los discursos que se articularon para consolidar el reconocimiento constitucional especial de indígenas y afrocolombianos, y así argumentar que la adopción de protecciones constitucionales especiales bajo el ropaje étnico generó una asimetría en el reconocimiento de las comunidades campesinas mestizas.

Al final, se concluye exponiendo la necesidad de consagrar una protección constitucional especial para la forma de vida campesina, describiendo el proyecto de acto legislativo que se encuentra actualmente en trámite en el Congreso de la República.

\section{La lucha campesina}

Los orígenes de la actividad del movimiento campesino se remontan a la necesidad que tuvieron de hacer reclamos sobre su forma de producción hacia el inicio del siglo XX, buscando disminuir su pago por el arrendamiento de tierras y la obtención de beneficios laborales. Es ahí, entonces, donde se empiezan a crear verdaderos conflictos de tierras, pues los campesinos fortalecen sus reivindicaciones expresándolas de manera activa y los terratenientes fortalecen sus fuerzas represivas ${ }^{2}$. Estas luchas estaban compuestas por los "trabajadores agrarios" , los cuales eran indígenas, afrodescendientes y campesinos mestizos:

Frente a este problema, Darío Mesa menciona que en la estructura agraria del país "prevalecía un grado precario de división del trabajo por parte de los principales dueños de la tierra, constituyendo esta una causa de retraso"

2 Uno de los conflictos más significativos de la época resulto ser aquel donde varios trabajadores exigían mejores condiciones laborales y que desencadenó la Masacre de las Bananeras en 1928.

3 Entiéndase así denominados en este trabajo al grupo de trabajadores compuesto por indígenas, afrodescendientes y campesinos mestizos que componían la fuerza laboral sobre las explotaciones de tierra existentes. 
(Mesa, 1972, p.24). Además, la ocupación de la tierra se conformaba del latifundio y del minifundio campesino, resaltándose que "en los latifundios se utilizaban distintos modelos de trabajo en los que se hacía uso de mano de obra indígena, mestiza y negra, con una fuerte sujeción del campesino sin tierra" (Tirado, 1998, p.57). Hechos que generarían el inconformismo generalizado de estos grupos sociales (Arboleda, 2013, p.8).

Es bajo este contexto que surge la Ley 200 de $1936^{4}$ como un instrumento normativo que buscó dar solución a las dinámicas conflictivas que se generaron alrededor de las relaciones con la tierra. Sin embargo, su implementación no trajo aportes significativos a los problemas estructurales en cuanto a la tenencia de la tierra debido la forma en la que la misma fue implementada y los efectos que sus disposiciones ocasionaron. Los gobiernos que sucedieron al de López Pumarejo no consideraron que la reforma agraria fuera transcendental para el desarrollo económico del país, por el contrario, supusieron que la misma impedía el cumplimiento de sus fines gubernamentales pues acrecentaba el movimiento de las masas, lo que hizo que se detuviera su correcta implementación (Zuleta, 1973, p.87) y, además, la presunción de propiedad privada prevista en su artículo primero sirvió para acrecentar la ola de violencia imperante, pues conllevó al cercamiento de grandes porciones de tierra por parte de los industriales para su apropiación y, por consiguiente, la profundización de la exclusión del campesinado ${ }^{5}$ (García, 2016, p.5).

4 Ley 200 de 1936 "Sobre el régimen de tierras", proferida bajo el gobierno liberal de Alfonso Lopez Pumarejo (1934-1938) denominado "La Revolución en marcha”, buscó realizar concesiones positivas sobre acceso a la tierra, clarificación de baldíos, la institucionalización de las formas de solución de los conflictos agrarios en consonancia con la modificación de la Constitución de 1886 en cuanto a la función social de la propiedad.

5 Dicha presunción se consagró en el artículo 1 de la Ley 200 de 1936:

"Se presume que no son baldíos sino de propiedad privada, los fundos poseídos por particulares, entendiéndose que dicha posesión consiste en la explotación económica del suelo por medio de hechos positivos propios de dueños, como las plantaciones o sementeras, la ocupación con ganados y otros de igual significación económica. 
Esta ola de violencia llevó al campesinado a sufrir desplazamientos, despojo de sus tierras y agitación de su movimiento. Bajo el desarrollo normativo que buscó reprimir la reforma agraria surgió la Ley 135 de 1961, la cual tenía dentro de sus motivaciones superficiales regular el derecho a la propiedad y cambiar la estructura social agraria del país, y dentro de las no tan evidentes, hacerle frente al desempleo que vivía el país a causa de los desplazamientos de trabajadores rurales que se trasladaban a las urbes y la necesidad de los industriales de utilizar la tierra para sus fines de lucro bajo la cobertura del modelo económico propuesto por la Alianza para el Progreso, donde se buscaban cambios en las estructuras sociales y económicas con el fin de impedir el estallido revolucionario en los países latinoamericanos (CNRR, 2010, p.213).

Dentro de la institucionalidad prevista para la implementación de dicha reforma nació la Asociación Nacional de Usuarios Campesinos Anuc-, que se convirtió en una de las organizaciones campesinas más importantes en cuanto a sus diferentes formas de lucha a favor de los derechos de los "explotados rurales" en la defensa de la tierra (Reyes, 1991, p.73) y como instrumento para presionar el cumplimiento de reforma agraria. (Pérez, 2010, p.19). La Anuc se define en su plataforma ideológica ${ }^{6}$ como una organización autónoma de campesinos asalariados, pobres y medios cuyas principales reivindicaciones están

"El crecimiento y la construcción de edificios no constituyen por sí solos pruebas de explotación económica, pero sí pueden considerarse como elementos complementarios de ella.

"La presunción que establece este artículo se extiende también a las porciones incultas cuya existencia sea necesaria para la explotación económica del predio, o como complemento para el mejor aprovechamiento de éste, aunque en los terrenos de que se trata no haya continuidad, o para el ensanche de la misma explotación. Tales porciones pueden ser, conjuntamente, de una extensión igual a la de la parte explotada, y se reputan poseídas conforme a este artículo”.

6 El texto oficial de la plataforma ideológica de la ANUC fue aprobado en Villa del Rosario Cúcuta el 5 de junio de 1971 iniciando así:

"Los campesinos de Colombia representados por sus delegados en el encuentro nacional campesino de 'Villa del Rosario de Cúcuta', nos comprometemos y 
encaminadas a la realización inmediata de una reforma agraria integral ${ }^{7}$ (Múnera, 1998, p.247).

Las comunidades indígenas contaban con el secretariado especial para asuntos indígenas dentro de la Anuc y así emprendieron una lucha común por la defensa de la tierra al considerar que esto fortalecería sus reivindicaciones individuales ${ }^{8}$ (Ortiz, 1999, p.344; Rojas, 2012, p.225).

La Anuc tuvo su auge en 1971, debido a que fue una organización que colaboró con la cohesión de la población campesina hacia un fin común

declaramos solemnemente como nuestra bandera de lucha la siguiente: plataforma ideología de la asociación nacional de usuarios campesinos de Colombia Anuc: la Asociación Nacional de Usuarios campesinos de Colombia, es una organización autónoma, de campesinos asalariados, pobre y medios, que lucha por una Reforma Agraria Integral y democrática; por la reivindicación del trabajador agrícola, por la elevación de su nivel de vida económico, social, cultural, y el desarrollo pleno de sus capacidades y que entiende que para superar el atraso económico del país y lograr el bienestar general del pueblo Colombiano es necesario romper las actuales estructuras de dominación internas y externas que han beneficiado a una reducida clase explotadora, mediante la lucha organizada y permanente del campesinado colombiano con la clase obrera y demás sectores populares comprometidos con el cambio estructural y la liberación total de nuestra patria de toda forma de dominación y coloniaje". Recuperado de: http://www.anuc.co/historia.asp

$7 \quad$ "Los grandes problemas sociales que estamos viviendo en estos momentos los campesinos, los arrendatarios, los aparceros, los hombres sin tierras no han sido creados por los dirigentes rurales. Están ahí, quiérase o no, por la incomprensión y por la mala distribución de la tierra. Esos problemas hay que solucionarlos con urgencia mientras pueda dárseles una solución Pacifica o correr el riesgo de que la gente se canse de esperar, se canse de sufrir y resuelva arreglar por sus propios medios su miseria y su desesperación”. Discurso de Francisco Barrios Gómez en representación de los delegados campesinos unidos en el capitolio en el I Congreso Campesino (Pérez, 2010, p.32).

8 "Consideramos, sin embargo, que nuestra posición no debe ser meramente defensiva; en el campo de las luchas populares los indígenas tenemos nuestras propias experiencias, y si bien es necesario que aprendamos de las luchas de otros sectores, también es cierto que nosotros tenemos algo propio para aportar. En el Cauca hemos visto por ejemplo que campesinos blancos, mestizos, negros, han recurrido a nuestros métodos de recuperación de las tierras, han considerado útiles nuestras formas de trabajo comunitario y hasta se han organizado en cabildos para orientar mejor sus luchas" (Gutiérrez, Molina, 2010, p.192). 
junto con los recursos y ayuda logística que recibían del Estado al ser parte de su institucionalidad. Así, se realizaron marchas, protestas y ocupaciones de tierras en búsqueda de la implementación real de la reforma agraria. Esta movilización campesina influenció fuertemente al movimiento indígena en cuanto al aprendizaje de formas de lucha para la reivindicación de sus propios territorios, que se desenvolvía dentro de un movimiento que tenía un común denominador: la condición de trabajadores del campo (Galvis, 2010, p.31).

A la par de este auge, intelectuales negros influenciados por el movimiento de los derechos civiles de los Estados Unidos, por la lucha contra la segregación en Sudáfrica y por la experiencia de la esclavitud en 1976 dan inicio al movimiento Cimarrón (Mosquera 2007, p.144), el cual surgió bajo el liderazgo del alumno de sociología Juan de Dios Mosquera, con el fin de reivindicar la igualdad para los negros colombianos en el marco del discurso de los derechos humanos. Su plataforma de lucha se fundamentaba en la reclamación de su derecho a la igualdad en la medida en que la gente negra se encontraba en lo más bajo de la escala social, excluida de educación, salud y de un trabajo digno, sumida en las más bajas condiciones de pobreza, características en todo similares con las de los que se llamaban simplemente campesinos. Buscaban que se les diera un tratamiento similar con los mestizos y blancos ${ }^{9}$ (Mosquera, 2007, p.157).

Dentro de esta lucha conjunta surge, en 1971, el Consejo Regional Indígena del Cauca - en adelante Cric-, conformado por el secretariado indígena de la Anuc y otras organizaciones campesinas que tenían

9 'El pensamiento que crea y difunde el movimiento cimarrón es el 'Cimarronismo', el cual se define como la conciencia de las comunidades negras en su lucha por el derecho a una vida digna en el pasado, presente y futuro. Es un nuevo pensamiento que se articula con la solidaridad hacia las naciones, comunidades indígenas, movimientos y organizaciones que luchan por la liberación social. Es un proyecto que reivindica y proclama el derecho de propiedad que tienen las comunidades negras sobre las tierras que ocupan; reivindica la igualdad de oportunidades de educación científica y humanística con base en la historia y la realidad étnico-cultural” (Herrán, 2010, p.192). 
como objetivo ayudar a los indígenas a participar dentro de la reforma agraria. Dentro de dicha organización se encontraron dirigentes indígenas y campesinos cuyo objetivo de lucha era el mismo: reivindicar la tierra $^{10}$ (Galvis, 2010, p. 26).

Sin embargo, varios sectores expresaron su descontento frente a las luchas campesinas e iniciaron una ofensiva que terminó consolidándose con la Ley 4 de 1973 (Pacto de Chicoral), el cual consistió en que el Gobierno, junto con algunos ganaderos y terratenientes, reorientó la política agraria y dentro de esa modificación prevaleció su modelo de desarrollo económico sobre el fortalecimiento social, lo que significó que finalizara el apoyo institucional, económico y político ${ }^{11}$ a los movimientos sociales - incluyendo la Anuc - y fortaleciera la ofensiva contra el movimiento campesino ${ }^{12}$ (Galvis, 2010, p.32).

10 “Entre 1971 y 1974 el Cric como organización asumió la doble bandera 'campesina' e 'indígena', y como tal participó en la recuperación de unas diez mil hectáreas de tierra, en la creación de tiendas comunales, cooperativas agrícolas y en los inicios de la educación bilingüe. En estos años el discurso y las estrategias para recuperar la tierra a través de invasiones fue el mismo utilizado por los campesinos de la Anuc en distintas partes del país, ocupando la tierra de noche para presionar una negociación entre los dueños y el Incora que a su vez compraba la tierra y la revendía a los campesinos imponiéndoles el modelo de cooperativas, capacitación y créditos blandos” (Ripoll, 2009, p.314).

11 "Esa falta de apoyo político se manifestó, primero que todo, en la resistencia impuesta por el gobierno de Pastrana Borrero a través del Ministerio de Agricultura a la creación de nuevas asociaciones municipales y departamentales. La resistencia también ocurrió por acto de omisión y desconocimiento de las asociaciones que ya existían en la época. Esto les fue bastante útil en el momento de tratar con asociaciones que no se sometían a los criterios de los funcionarios del ministerio. Así, la creación de esas iniciativas organizativas se convirtió en una verdadera batalla entre las masas campesinas y los funcionarios de la división de organización campesina del Ministerio de Agricultura, los alcaldes y los gobernadores. La conclusión de ese primer choque fue el desmonte de las políticas agrarias mediante el Acuerdo de Chicoral, que dio origen a las leyes 4 y 5 de 1973, en las que se impusieron los criterios e intereses de los terratenientes por encima de los intereses y necesidades nacionales” (Perez, 2010, p.21). "Con este tipo de estrategias fueron logrando la división de la Asociación, que hasta esa fecha era la agremiación con mayor poder de convocatoria y de 


\section{El giro étnico}

Después del acuerdo de Chicoral comenzó la fragmentación por grupos del movimiento campesino, siendo el indígena ${ }^{13}$ el primero en separarse, esto por una divergencia en su forma de lucha. Aunque el objetivo era el mismo - la obtención de la tierra-, la forma se bifurca entre indígenas y campesinos. El indígena, por un lado, opta por un fundamento de etnicidad ${ }^{14}$, y por el otro, el campesino sigue con una

envergadura nacional. No es de extrañarse, pues no había otra organización con tal capacidad para la movilización y la promulgación de la presión política por parte de los trabajadores del campo en demanda de sus reivindicaciones más sentidas. La lucha no se limitó, entonces, a enfrentar enemigos tradicionales del campesinado en su lucha por la tierra y demás reivindicaciones, sino que se convirtió en un escenario de lucha interna entre los diferentes sectores políticos de la izquierda colombiana. En realidad, este sector político aspiraba, por diversos caminos, métodos y tácticas, a obtener el apoyo del campesinado para enfrentar y desarrollar una lucha contra el régimen y su sistema de instituciones" (Pérez, 2010, p.61).

13 Así lo expreso el movimiento indígena en 1974: "Los paeces, guambianos, coconucos y demás indígenas del Cauca vivimos en las montañas, en las haciendas y resguardos. Somos campesinos [...] [S]omos la mayoría del campesinado del Cauca [...] no tenemos escuelas suficientes, ni puestos de salud, ni caminos, ni tierra donde trabajar. O las parcelas que tenemos son muy chiquitas para dar de comer a los hijos [...] Los indígenas de parcelas chiquitas, los terrajeros, los peones y los comuneros estamos todos explotados. Como los campesinos de otras partes. Igual que los campesinos de toda Colombia [...] [pero también], Los paeces, guambianos y demás somos indios. Porque somos descendientes de las naciones indígenas que habitaban estos territorios siglos antes de que llegaran los invasores desde España [...] Somos indios, 'naturales' como dicen, y tenemos derecho a nuestras tierras [...] Apreciamos estas costumbres, estas lenguas, esta historia que nos unen y fortalecen. Somos indios y creemos que ser indio es bueno" (Laurent, 2010, p.41).

14 "La secretaria de asuntos indígenas delibera al margen de los sucesos del III Congreso. En la ponencia que presenta a la asamblea plenaria, platea que aunque existan rasgos comunes generales con la población campesino, su particularidad determina aspectos específicos propios. Aclara que no se trata de armar tolda aparte sino de insistir en esa diferenciación potencial aprovechable que será el aporte de las comunidades indígenas en la lucha por la liberación de los explotados de Colombia. Se reconoce el carácter defensivo que han tenidos sus luchas hasta el momento pero se arguye la progresión que se les está dando hacia el desarrollo 
reivindicación de clase, es decir, en clave de la búsqueda de la igualdad con los demás ciudadanos ${ }^{15}$ (Castillo, 2005, p.230), pues las exigencias que hacían los campesinos eran de tipo económico: acceso a la tierra, agua, salarios, salud, educación. La estrategia de lucha era agrupar a todas las clases oprimidas rurales bajo un mismo ideal de recuperación de la tierra dentro del discurso socialista o de reivindicaciones de clase (Castillo 2005, p.264).

En el momento de la fragmentación del movimiento campesino, los indígenas, al continuar en la misma variable de reivindicación (la defensa del territorio), adoptan el discurso étnico cuando se dan cuenta de que esta forma de lucha les había funcionado para la defensa de su territorio desde las ocupaciones coloniales; por lo tanto, argumentan que su cosmovisión es diferente a la de los campesinos y por esto se debían separar $^{16}$ (Escobar, 1982).

La percepción campesina de la reivindicación de tierra estaba a favor de obtener titulación y división de tierras para la explotación y producción

de una nueva sociedad. Por último se establece su interés por la participación activa dentro de la Anuc pero no a través de la unión forzada desde arriba sino del fortalecimiento de la organización indígena bajo la coordinación general de la Anuc" (Escobar, 1982).

15 Para esta nueva identidad política se revitalizaron y reinterpretaron ciertas tradiciones, no para añorarlas, sino para que la interpretación del pasado sirviera como política del presente (Jimeno, 1998, p.104).

16 Así lo expresa el movimiento indígena en el Primer Congreso Indígena Nacional: "Llamamos indigenismo a la posición que ante el avance del capitalismo se niega a enfrentarlo. Pretende mantener las comunidades aisladas de los procesos sociales, económicos, culturales y políticos, que de todas maneras penetran a las comunidades y las modifican. Trata de separar las luchas indígenas de las luchas de los demás explotados y oprimidos, considerándolas de naturaleza muy diferente. [...] Plantea también el «indigenismo cósmico» que el problema fundamental de nuestros países es la opresión racial, ya que lo de las clases sociales hace parte de las ideas venenosas traídas de Europa. La lucha fundamental habría que darla en el terreno de la ideología combatiendo todas las ideas «blancoides» e imponiendo la mentalidad cósmica de nuestros antepasados, que nos salvara a nosotros los indígenas y también al resto del mundo" (Herrán, 2010, p.185). 
de excedentes, mientras que la indígena tenía como objetivo obtener tierras no para dividirlas, sino para que les sirvieran como medio para su conservación cultural. Por eso se defendía en gran medida la figura del resguardo. Es en esta opción política donde aparece la etnicidad como herramienta de lucha del movimiento indígena (Castillo, 2005; Galvis, 2010).

Así, la opción de la etnicidad era entendida por el movimiento indígena no como un tradicionalismo, sino como una estrategia de agrupación de la comunidad y de reivindicación de sus derechos territoriales ${ }^{17}$ (Jimeno, 1998, p.104).

Por su parte, el movimiento Cimarrón escoge seguir con el discurso de lucha de clase con reivindicaciones en clave de igualdad fundamentado en la lucha de los derechos civiles y políticos. Esto genera una ruptura en el movimiento, y de manera similar a como ocurrió con el indígena, parte del mismo prefirió tomar la bandera étnica como una mejor estrategia de reivindicación de derechos (Cunin, 2003, p.357). Es así como una parte del movimiento negro busca separarse de la pelea entre las guerrillas izquierdistas y el Estado colombiano a través de la opción por la etnicidad, siendo este el movimiento campesino negro de la zona plana del norte del Cauca (Pulido, 2010, p.264). Surge entonces el proceso de comunidades negras - PCN - al comienzo de la década de los setenta a raíz de una doctrina religiosa que reivindica la particularidad

17 "Sabemos que los indígenas descendemos de los pueblos que habitaron originalmente este continente y que crearon en muchos casos civilizaciones bastante adelantadas, destruidas luego por la conquista española. Nuestros pueblos fueron exterminados en gran parte por los europeos, pero los que hemos logrado sobrevivir conservamos aún, o hemos desarrollado, una serie de características específicas como un territorio propio, nuestra lengua, nuestras tradiciones y costumbres, manifestaciones artísticas propias, además de una organización social (al menos en parte) autónoma. [...] Consideramos de nuevo su insistencia en que los indígenas poseemos una identidad propia, enraizada en las sociedades de nuestros antepasados y con capacidad de seguirlos desarrollando autónomamente” (Herrán, 2010, p.187). 
de los negros. Sostienen que no son campesinos ni obreros y que por lo tanto merecen un trato diferente (Castillo, 2007, p.184).

Finalmente, los grupos que optaron por la diferenciación étnica fundamentaban esta pretensión en una historia de persecución tradicional y en sus rasgos diferenciadores para hacer demandas desde lo cultural (Pulido, 2010, p.265).

De esta manera, hacia mediados de los años ochenta surge la Asociación Campesina Integral del Atrato - Acia - ${ }^{18}$, en las inmediaciones de este río, como una estrategia organizativa que por primera vez realiza su plataforma de lucha sobre las consideraciones de ser un grupo étnico con un territorio, prácticas tradicionales de producción y una identidad cultural específica (Restrepo, 2013, p. 37).

Dentro de las razones por las que surge dicha forma de organización se encuentran las amenazas de despojo de sus recursos, pues se habían otorgado concesiones o permisos de explotación de sus recursos ambientales a diferentes compañías junto con el acompañamiento de órdenes religiosas, que buscaban propiciar organizaciones de base a partir del estudio religioso que hicieron sobre la organización de las comunidades negras presentes en la zona. Otro aspecto importante fueron los estudios realizados por un proyecto de cooperación técnica internacional con Holanda conocido como Diar —Desarrollo Integral Agrícola Rural-, que se inició en 1980. Estos estudios tenían una asignación presupuestal importante y, por lo tanto, cierto grado de independencia, dedicándose al estudio de las características y vocación del suelo del medio Atrato y los modelos productivos de la población campesina ne-

18 "La Acia constituye, sin duda, la primera organización en Colombia (y en el continente) que se define en términos de los otros étnicos de la nación (Briones, 2002; Segato, 2007), esto es, desde un argumento que apela a la diferencia y ancestralidad cultural para reivindicar derechos territoriales e identitarios" (Restrepo, 2013, p.37). 
gra. Así, dichos estudios se constituyeron en condiciones de posibilidad para el giro étnico afrocolombiano ${ }^{19}$ (Restrepo, 2013, p.69).

Sin embargo, a pesar de esto, la Acia en sus primeros años se entendía como una organización campesina. Prueba de esto es que, en 1987, se afilió a la línea oficialista de la Anuc, pretendiendo que con su pertenencia a dicha organización sus reclamos fueran escuchados por el Gobierno (Restrepo, 2013, p.69):

Como lo ha venido planteando la Acia, los campesinos del medio Atrato queremos la titulación comunitaria de las tierras, para evitar que vengan los colonos y terratenientes y nos dejen sin nada (El Atrateño, 12 junio 1988, p.4) (Restrepo, 2013, p.70).

El 27 de agosto de 1988, en San Antonio de Padua, la Acia realizó su primera reivindicación fundamentada en argumentos étnicos y en lo que establece en Convenio 169 de la OIT ratificado por Colombia mediante la Ley 31 de $1967^{20}$, siendo este el momento en el que se crista-

"En este sentido se puede afirmar que el Diar contribuyó a gestar las condiciones de posibilidad discursiva que instaura una representación política y académica novedosa de las poblaciones negras como un grupo étnico. Lo impensable de la etnicidad para las 'comunidades negras' se hace pensable a través de las labores investigativas del Diar en torno a los modelos productivos regionales y su lectura a la luz de la noción de territorio. Y esto se encuentra por vez primera en el Acuerdo de Buchadó: “El acuerdo de Buchadó es el antecedente de la Ley 70 porque usted no encuentra antes ninguna alusión a los derechos territoriales. Ni siquiera en el Paro. [35] Aparece para mí el antecedente inmediato de la Ley 70 es ese. Porque aparece una reivindicación, y aparece lo de las tierras comunales... que era un impensable. Entonces aparece un hecho totalmente nuevo". Entrevista con Enrique Sánchez, sociólogo Colombiano que trabajo en el Pacífico desde los años 80 (Restrepo, 2013, p.66).

Resulta ilustrativo revisar esta declaración realizada por el movimiento negro: "Insistimos que se adelante una Titulación Comunitaria de los territorios que ancestralmente hemos ocupado las comunidades campesinas negras e indígenas de esta zona, mediante la cual se legalizaría la posesión que hemos venido ejerciendo tradicionalmente, a través de un Titulo Comunitario que reconocería 
liza la reivindicación del movimiento afrocolombiano como un movimiento étnico y no campesino ${ }^{21}$ (Restrepo, 2013, p.73). En este punto es importante ver cómo la construcción de una identidad étnica no es un factor estático o que venga dado solo en algunas comunidades. La identidad cultural se genera a través de las relaciones entre los grupos sociales, sus demandas frente al Estado y de acuerdo con los diferentes acontecimientos de la historia. Es una posición política dinámica, tal y como se evidencia en la lucha afrocolombiana, donde inicialmente se pensaría que estas comunidades no tenían características de etnia, pero esta se fue forjando con el paso del tiempo y con la decisión de la comunidad de apostarle a la misma como estrategia de lucha (Restrepo, 1998, p.144).

Así, los indígenas y los afro optan por usar la cohesión como estrategia de lucha a través de la herramienta de la identificación étnica, y tam-

a las comunidades como propietarias del globo de terreno señalado por el Art. 1 del Acuerdo 20 del 9 de junio de 1988, de la Junta Directiva de Codechocó, el cual incluye, además de las parcelas familiares, los bosques, la ciénagas de uso comunitario con todos sus recursos naturales. Una Titulación Comunitaria como la que proponemos, garantizaría el manejo racional y el aprovechamiento sostenido de los Recursos Naturales en la región, pues se respetarían los usos culturales que damos a la tierra las comunidades negras, evitando la explotación irracional que se viene presentando por la colonización indiscriminada, lo cual afecta gravemente el equilibrio del ecosistema, de por sí tan frágil. Además, la propuesta tiene respaldo jurídico en el espíritu de la Ley 31 de 1967, que aprueba el Convenio relativo 'a la protección e interacción de las poblaciones indígenas y de otras poblaciones tribales y semitribales en los países independientes'. Los habitantes del Medio Atrato somos descendientes directos de las tribus africanas que fueron traídas como esclavas durante la Colonia, sin su libre consentimiento. Igualmente, nos asimilamos a lo expuesto en el numeral 2 del Art. 1 de la Ley 31 de 1967, puesto que hemos venido reproduciendo y construyendo una cultura con base en la herencia de nuestros ancestros africanos, en la cual tenemos formas culturales particulares de relacionarnos con la tierra y los recursos naturales en general" (Acia, 1988, p.20 citado por Restrepo, 2013, p.71).

${ }_{21}$ "Lo que hoy es un sentido común en el ámbito jurídico y político, esto es, que las poblaciones negras constituyen un grupo étnico era un impensable hacia mediado de los ochenta, y es en este foro de titulación de tierras en San Antonio de Padua que cristaliza por vez primera" (Restrepo, 2013, p.73). 
bién como forma de desactivar la asimilación de los proyectos étnicos con la insurgencia armada y evitar su represión (Pulido, 2010). Los campesinos, por su parte, continúan con sus estrategias de reivindicación - tomas de tierras, marchas pacíficas, alianzas con determinados grupos marginados-, las cuales estaban concentradas en exponer la necesidad de una reforma agraria que comportara la redistribución de la tierra (Múnera, 1998, p.259). La opción por la identificación étnica movilizó recursos académicos, legales e institucionales para relacionar tanto al movimiento de indígenas como de afrocolombianos de cara a sus reivindicaciones sobre la tierra (Galvis, 2010, p.28).

\section{El Movimiento Social Campesino y las reivindicaciones étnicas en la Constitución de 1991}

El movimiento indígena llegó fortalecido a la Asamblea Nacional Constituyente y prueba de esto fue lograr que se eligieran dos delegatarios suyos: Francisco Rojas Birry y Lorenzo Muelas. El discurso de sus reivindicaciones estuvo fundado en direcciones opuestas: igualdad y unidad política, por un lado, y diferencia y autonomía política, por el otro. En la primera de estas direcciones, el discurso se centró en evidenciar la discriminación que vivieron las comunidades indígenas en razón a la diferencia existente entre su cultura y la de las mayorías, por lo que se demanda un reconocimiento en términos de igualdad con el resto de la población, discurso adoptado de la lucha campesina (Bonilla, 2006, p.127).

En la segunda dirección, se hace énfasis en los elementos que diferencian a las comunidades de la mayoría y se pide protección para esta diferencia, pues se condenan las pretensiones del Gobierno de asimilarlos al resto de la sociedad. Se pide, entonces, que se reconozca que Colombia no es un país culturalmente homogéneo y que las pretensiones de hacer ver la cultura occidental como superior a la indígena por parte del Estado debían desaparecer (Bonilla, 2006, p.127). Así mismo, buscan 
el reconocimiento de una propiedad colectiva sobre los territorios ancestrales y el establecimiento de una jurisdicción indígena. Su objetivo era que, por medio del reconocimiento de la multiculturalidad del país en la Constitución, se visibilizara a la sociedad y se les diera aceptación dentro de la misma.

Hubo una tensión entre la pretensión de igualdad y la de autonomía, donde es más fácil evidenciar que la lucha indígena seguía siendo, en todo caso, una lucha campesina, en el sentido que seguían con exigencias en clave de igualdad, aunque fortalecían su argumento en lo que los hacía diferentes del campesino mestizo (Bonilla, 2006, p.127).

En resumen, las demandas del movimiento indígena dentro de la ANC eran principalmente tres: autonomía territorial, respeto a la diferencia cultural y participación política en las decisiones que le afectaran al Estado (Castillo, 2005, p.429). Estas demandas fueron sustentadas en la legislación internacional favorable a los indígenas, principalmente en el convenio 169 de la OIT, utilizando su artículo primero para ratificar la particularidad de las comunidades indígenas desde el concepto de pueblos indígenas y tribales que ahí aparece, y sobre lo cual fundamentan su demanda para buscar la consagración de una categoría diferencial, exigiendo identidad cultural, autonomía, propiedad territorial y participación en asuntos de Gobierno (Castillo, 2005, p.430; Sánchez, 1993, p.37; Peñaranda, 2015, p.28) 22 .

22 Esta visibilizarían estaba fundamentando una de las pretensiones principales del pueblo indígena cual era la de hacer ver que ellos como pueblo dentro de la nación colombiana tenían rasgos diferenciadores que hacían necesaria una protección que se viera reflejada en la autonomía en el manejo de sus tierras debido a que esto potenciaría y elevaría la expresión de sus tradiciones, en esta medida su discurso étnico se fundamentó en ser cuantitativamente menos en comparación con la población colombiana y como tal víctimas de discriminaciones que se basaban en esta diferencia, es decir, el reconocimiento de la diferencia en una minoría se planteaba como el argumento que debía llevar a establecer esta figura de protección especial mediante un discurso que buscaba incentivar una mejor comprensión de la Nación colombiana (Peñaranda, 2005, p.28). Aún cuando la expresión de ser una minoría cuantitativa fue importante, después de la separación 
Los reconocimientos alcanzados por parte de las comunidades indígenas se han visto permeados hasta el día de hoy por la tensión existente entre autonomía e igualdad de trato por parte del Estado (Bonilla, 2006, pp.127, 129), esto es, la tensión existente entre la legitimidad que detenta el Gobierno para regir las comunidades indígenas e imponer sus planes administrativos sobre las mismas y la autonomía con que estas cuentan y que de todos modos emana del Estado (Bonilla 2006, pp. 131, 136). Dicha tensión, en realidad, se resolvería si se aceptara que la lucha indígena es la misma que la lucha campesina a través de las reivindicaciones de reconocimiento estatal en clave de igualdad.

En lo que tiene que ver con las comunidades negras, como se mencionó, surgieron dos tendencias dentro de sus organizaciones. La primera, de tendencia más reciente, la cual luchaba por la reivindicación identitaria - movimiento Acia-, y la segunda, que luchaba por la igualdad de la población negra con el resto por la influencia recibida del movimiento de los derechos civiles y políticos - movimiento Cimarrón- (Castillo 2007, p.195). Así, los que estaban en la ola de la diferencia buscaban elegir un candidato para la ANC que representara a las negritudes y los otros buscaban lanzar candidatos dentro de las tendencias políticas de la época.

El movimiento Cimarrón decide como estrategia lanzar un candidato dentro de la Unión Patriótica, lo cual no funciona, pues el postulante seleccionado, Juan de Dios Mosquera, no resulta elegido dentro de ese partido para ir a la ANC (Castillo, 2007, p.195). Esto hace que en los miembros de Cimarrón haya una ruptura, pues comienzan a pensar que necesitaban pasar del discurso de la igualdad al de la diferencia, tomando este último como otra alternativa en la lucha contra la discriminación a la que sometían al afrodescendiente, por lo que la línea identitaria se vio fortalecida.

La academia en las comisiones preparatorias de la Constituyente defiende la identificación étnica de los afrocolombianos al decir que fueron 
víctimas del mestizaje republicano tanto como los indígenas, pero que no contaron con las mismas herramientas de estos últimos, tales como la figura del resguardo y posteriores instrumentos legales, que les sirvieron para su defensa. Los afrodescendientes, así como los indígenas, tenían una filiación ancestral con la tierra, pero esta solo la pudieron defender a través del cimarronaje. Dijeron, entonces, que su exclusión como etnia constituiría una violación a la igualdad (Pulido Londoño, 2010, p.272; Restrepo, 2013).

Posteriormente, la tendencia étnica del movimiento negro, previendo que Rosero no saliera elegido como delegatario por la negritudes, hace una alianza con Lorenzo Muelas, con lo cual se establece una coalición electoral interétnica entre indios y negros que consistía en que los indios representarían los intereses de los negros en la ANC y como contraprestación las comunidades negras apoyarían a Rojas Birry con votos para que quedara elegido como delegatario (Castillo 2007, p.201; Sánchez, 1993).

Finalmente, a pesar de que la academia buscó visibilizar la etnización de las comunidades afrodescendientes, su participación en la ANC se diferenció sustancialmente de las comunidades indígenas en la medida en que no alcanzaron una representación directa como etnia. Esto, porque no había una consolidación suficiente del movimiento afrocolombiano como si lo había del movimiento indígena; asimismo, la visibilización que tenía el movimiento indígena era mucho mayor debido a aspectos coyunturales ${ }^{23}$ previos a la ANC y por toda la estrategia de

del movimiento indígena con el campesino y su incursión en ámbitos nacionales e internacionales lo que más primó fue su caracterización como minoría cultural, es decir, el realizar descripciones de las categorías que los diferenciaban tales como lengua, religión, cultos religiosos entre otros, factor esencial en el establecimiento de una minoría sobre el aspecto numérico.

23 Durante los meses de conformación de la ANC se realizó una manifestación contra la conmemoración que se iba a dar del encuentro de dos mundos, lo que cohesiono mucho a los grupos sociales que buscaban hacer sus reivindicaciones en 
lucha identitaria que habían iniciado de tiempo atrás. Es por eso que la alianza mencionada resultó muy importante dentro de la constituyente para los intereses de los afrodescendientes.

En definitiva, este proceso culmina en la constituyente con la adopción del artículo 55 transitorio, que es desarrollado por una comisión especial conformada por el Gobierno y representantes de comunidades negras. En dicha delegación, a través de diferentes debates, los comisionados especiales y los funcionarios gubernamentales construyeron los términos y contornos de la etnicidad negra (Restrepo, 1998, p.346). Es así como se constata que el reconocimiento étnico de los afrodescendientes se logró gracias a la visibilización que se dio por parte de diferentes actores y de sus características diferenciadoras a través de una construcción temporal y política (Restrepo, 1998, p. 346).

Dicho reconocimiento termina siendo similar al de las comunidades indígenas, pues en la reglamentación del artículo 55 transitorio, a través de la Ley 70 de 1993, la identificación étnica de los afrocolombianos se hace utilizando las categorías del reconocimiento étnico indígena: vida comunitaria, tenencia comunitaria de la tierra y prácticas de producción inmemoriales (Pulido, 2010, p.277).

\section{Asimetría en el proceso constituyente}

El movimiento de los campesinos que no optaron por la estrategia de la diferenciación étnica llegó muy debilitado a la constituyente ${ }^{24}$ por las siguientes razones históricas: (i) la falta de apoyo y posterior

clave de identidad étnica, el apoyo de los académicos indigenistas, los convenios internacionales que se estaban produciendo a su favor entre otros.

"Para los inicios de los noventa, el movimiento social estaba muy debilitado. Solamente había expresiones muy locales que no podían actuar fuera de su vereda. Fue tan dura la situación que añoramos la época de los setentas, cuando era tal la fortaleza del movimiento campesino y social que los diferentes actores 
persecución por parte del Estado, (ii) la división ideológica al interior del movimiento, (iii) la irrupción de la izquierda para utilizarlos, (iv) el asesinato de sus miembros más representativos ${ }^{25}$, (v) la estigmatización de sus miembros como pertenecientes a grupos subversivos ${ }^{26}$, (vi) la persecución del paramilitarismo ${ }^{27}$, y (vii) la pérdida de enfoque de la organización en sus reivindicaciones por la necesidad de defensa frente a las persecuciones sufridas (Rivera, 2016, p.2; Pérez, 2010, p.172).

armados no lograron penetrar y causar el caos. No obstante, ese no fue el caso en ese momento, pues con un movimiento campesino supremamente debilitado y sin la posibilidad de acceder a los créditos, el siguiente paso fue la pobreza, y esa fue toda la papaya que necesitaron los alzados en armas para poder entrar y hacer lo que siempre han hecho" (Pérez, 2010, p.172).

"En este departamento ocurrieron varios hechos que avergonzarían a cualquier gobierno. Fue allí donde bandas de pájaros armados, junto con la Policía carabinera y DAS rural, asesinaron, quemaron y torturaron a varios dirigentes campesinos como Ismael Bertel, Ignacio De La Rosa Tordecilla, Eduardo Mendoza y algunos campesinos de Chuchurubí en el año de 1974. En este año también se llevaron a centenares de campesinos colonos, aparceros y arrendatarios a la cárcel. Las órdenes fueron dadas por los terratenientes Ospina, Gallino, Vargas, el señor Alfonso Espatt y los demás miembros de la camarilla de Córdoba, quienes lanzaron una ofensiva aprovechando el Estado de sitio contra la organización" (Pérez, 2010, p.98).

26 “Así, les explicamos que la asociación manejaba una línea de clase, no una línea de partido como ellos querían, por lo que no podíamos recibir las directrices de partido que querían imponernos; ahora bien, no se puede negar que algunos grupos alzados en armas participaron de alguna forma en la organización campesina, pero su presencia era mínima en algunos sectores de la masa, mas no en la dirección de la Anuc. Sin embargo, debido a la presencia de las guerrillas en Sucre se empezó a vivir un problema de señalización. Nos miraban no como organización campesina, sino como guerrilleros, hecho que contribuyó a cierto acoso institucional innecesario, pues por la zona nunca hubo campesinos alzados en armas" (Perez, 2010, p.166). En 1976 y 1978 se profieren dos decretos de estado de sitio que buscaron perseguir y criminalizar al movimiento campesino (Pérez, 2010).

27 "Frente a la arremetida de la fuerza pública y la represión hacía nuestros dirigentes, el Comité Ejecutivo de la Anuc decidió redactar un documento que denunciara nuestra situación, pues el ambiente no era muy halagador para los Usuarios Campesinos. Este documento se realizó porque, además de la 
Los anteriores factores han sido recopilados y referenciados como causantes de daños al movimiento campesino, uno de los cuales se encuentra descrito como "descampesinización":

En El Paso [Cesar] ya casi no hay campesinos porque muchos murieron en el conflicto y porque los hijos de esos campesinos perdieron sus tierras por lo que no tienen dónde trabajar. Aquí hay mucho temor de morir por reclamar las tierras que nos pertenecen. Se perdió la tradición campesina en el municipio por la llegada de los proyectos mineros y los jóvenes han iniciado a trabajar en las minas dejando de lado el campo. Da pesar recordar eso porque esta fue una zona de muchos cultivos familiares, de trabajo en comunidad, de mano cambiada, de festividades campesinas. [A] nosotros no solo nos mataron los líderes, sino que nos mataron el ser campesinos (Herrera, 2016, p.10).

Este daño, en cuanto a su forma de vida o su reconocimiento como ser campesino, puede vislumbrarse como uno de los factores más importantes por los cuales el movimiento campesino no logró implementar una estrategia de lucha similar a la de indígenas y afrocolombianos.

contraofensiva del DRI y de las políticas agrarias, nuestra Asociación tuvo que soportar no sólo la persecución y el hostigamiento, sino que la violencia llegó al asesinato de nuestros dirigentes y a la quema de cultivos: La Asociación Nacional de Usuarios Campesinos de Colombia ha venido denunciando, desde la creación de las primeras asociaciones departamentales del Valle del Cauca y Sucre en el año 1969, la soterrada violencia y represión de los terratenientes contra los pobres del campo, pues ellos utilizan sus organismos privados paramilitares junto con los oficiales del Estado para impartir su ley. En las respectivas denuncias siempre hemos contado con la solidaridad de los obreros, profesores y estudiantes pobres, pequeños comerciantes y barrios populares, sacerdotes progresistas y algunas personalidades democráticas de Colombia y el exterior. Sin embargo, el Estado colombiano jamás se ha pronunciado a ningún nivel ante las denuncias que siempre se han caracterizado porque han sido concretas e irrefutables. No nos extraña la actitud de los representantes del Estado, ya que tenemos claro que es la maquinaria represiva defensora de los intereses de las clases dominantes y, en nuestro caso, de la clase terrateniente y la burguesía intermediaria, así como de un reducido número de familias que ostentan el poder económico, político y militar. Documento de denuncia pública. Julio 21 de 1975” (Pérez, 2010, p.63). 
Como se ha descrito en los diferentes procesos vistos, los indígenas y los afrocolombianos contaron con herramientas de diferentes índoles tales como foros académicos, congresos y estudios realizados por antropólogos y sociólogos, quienes buscaron contribuir a su identificación étnica como estrategia de lucha, contrubuciones que los campesinos mestizos no pudieron tener, pues aunque su organización sirvió de base para estos movimientos que se diferenciaron étnicamente, no logró fortalecerse lo suficiente para estructurar sus demandas como movimiento social en la ANC (Escobar, 1991; Pulido, 2010).

Así, el constituyente Marco Antonio Chalita, perteneciente al M-19, en las discusiones del artículo 64 constitucional —que consagró la protección a los campesinos-, en sesión plenaria del 10 de junio, después de exponer un discurso a favor de los campesinos de Colombia donde evidenció sus principales problemas, pidió que dentro de la asamblea se tomaran medidas para aliviar la situación de pobreza y miseria de 260 mil familias que no habían alcanzado a obtener un lote de tierra, mediante la realización de una verdadera reforma agraria, créditos, educación, refinanciamiento y apoyo a una nueva organización en el campo de las empresas comunitarias. Se buscó una redistribución en la propiedad de la tierra, mediante medidas afirmativas que pusieran al campesinado en un plano de igualdad (Discusión plenaria 10 de junio, p.4).

La propuesta del delegatario Chalita se centró en que con el fortalecimiento del campo se mejoraría la empresa colombiana, se erradicaría la pobreza, disminuiría el desempleo, se evitaría que los campesinos entraran a hacer pate de grupos insurgentes, para así buscar la paz en la medida en que el Estado reconociera las necesidades de los campesinos y las supliera. Todo en clave del discurso de la producción (Artículo 64 sesiones de las comisiones, p.2). Además, pidió que se resolviera el problema de la tenencia de la tierra: "Yo pienso que todos los colombianos desde el momento en que nacemos, desde el momento en que venimos, llegamos a este mundo, tenemos el derecho a un pedacito de tierra” (Artículo 64 sesiones de las comisiones, p.11). 
Finalmente, en la votación del artículo 64 iba a quedar la palabra garantizar, pero por catorce votos en contra y nueve abstenciones no pasó. Quedó entonces la palabra promover, que resulta bastante abstracta y susceptible de darle el contenido que se quiera dependiendo de los intereses buscados. Como verbo rector de la norma es inoperante, pues no obliga al Estado a nada, simplemente a promover sin acciones puntuales, lo que muestra que a diferencia de los indígenas y afrodescendientes, las obligaciones jurídicas del Estado colombiano a favor de los campesinos eran vagas y con una gran dificultad de definición, reconocimiento que por lo demás resulta muy injusto cuando en el fondo las demandas eran las mismas.

Esta dinámica constituyente muestra la asimetría en el reconocimiento del movimiento campesino, pudiéndose catalogar la misma como un reconocimiento por niveles. Así, en un primer nivel, se encontraron las comunidades indígenas, cuyo reconocimiento alcanzó la consagración de reconocimientos positivos a nivel constitucional enfocados en la afirmación de sus relaciones especiales con la tierra y la protección de su cultura tradicional; en segundo nivel, las comunidades negras, quienes alcanzaron un parágrafo transitorio; y en un tercer nivel, las demandas del campesino mestizo, cuyo reconocimiento se restringió a una mención de los mismos como componente del sistema económico Colombiano.

\section{Corrección de la asimetría: necesidad de un reconocimiento constitucional especial de la forma de vida campesina}

La consagración positiva de la protección constitucional especial para los grupos indígenas y afrocolombianos estuvo fundamentada en elementos subjetivos y objetivos, los cuales en su mayoría eran detentados por el campesino mestizo ${ }^{28}$. Dentro de los subjetivos se encuentran su

28 "Así se evidencio en el encuentro de Zonas de Reserva Campesina realizado en Corinto Cauca en marzo de 2012, en el que indígenas, afrocolombianos y 
autoidentificación como grupo diferenciado, la voluntad de preservar su cultura, la forma de relacionarse con su territorio; dentro de los objetivos, se encuentran el poseer elementos culturales distintivos del resto de la colectividad de la nación, contar con una ascendencia particular y conservar prácticas de un derecho propio, entre otros (Restrepo, 2013).

Esta consagración especial para grupos indígenas y afrocolombianos generó una asimetría en el reconocimiento de las comunidades campesinas que tuvo como efecto que muchas de ellas no tengan niveles de protección similares a estos grupos diferenciados étnicamente ${ }^{29}$,tales como el derecho a ser consultados con anterioridad a la realización de proyectos agroindustriales en sus territorios, la protección especial en cuanto a las afectaciones de propiedad en su territorio y el reconocimiento a nivel constitucional sobre su forma de vida comunitaria.

Dentro de las causas de dicha asimetría se encuentra que para la época de la constituyente estos elementos subjetivos y objetivos se visibilizaron para comunidades indígenas y afrocolombianos y se acallaron casi por completo para comunidades campesinas que también los detentan; asimismo, dicha falta de reconocimiento también está fundamentada en que el campesino mestizo hizo sus reivindicaciones con base en lo económico y no en lo cultural o étnico, como sí lo hicieron las comunidades indígenas y afrocolombianas (Ferro, 2013, p.109).

En el contexto actual comienzan a aparecer valiosos estudios e iniciativas que buscan fortalecer las reivindicaciones campesinas en sede cul-

campesinos coincidieron en la necesidad de pensar en territorio ‘entreverados' que permitan a futuro, escenarios más fluidos de co-manejo, sin las fronteras, muchas veces artificiosas, del reconocimiento estatal de los derechos a la propiedad colectiva o individual” (Ferro, 2013, p.92).

29 “[...] han sido muchos los logros en términos de defensa de los territorios basada en los derechos a la diferencia: los negros tienen cerca de 5.200.000 hectáreas en territorios colectivos, y existen más de 30 millones de hectáreas en resguardos para los indígenas” (Ferro, 2013, p.109). 
tural, a través del estudio de su forma de vida y rasgos diferenciadores. Un ejemplo se encuentra en el Movimiento de los Trabajadores Rurales Sin Tierra del Brasil -MST_-, quienes han cambiado el discurso de sus reivindicaciones: en lugar de solicitar la titulación de la tierra, buscan obtener un derecho de explotación de la misma, permitiendo que el título se quede en manos del Estado. Lo anterior impulsa una concepción de la tierra más como una vía para la subsistencia que como una vía para negociar, buscando la reconstitución de la identidad campesina que fue desdibujada por los factores que han sido descritos (Ferro, 2013, p.92).

Así mismo, se ha estudiado el modelo económico que las comunidades campesinas proponen a raíz de su forma de relacionarse con el territorio que se centra en conceptos como el de soberanía alimentaria ${ }^{30}$, el cual hace que las comunidades campesinas se cohesionen culturalmente, pues realizan cultivos tradicionales alrededor de los cuales gira su forma de vida y transforman la concepción que se tiene sobre ellas (Silva, 2012). Lo anterior implica que los campesinos deban tener un acceso mayor a la tierra, exaltando los conocimientos ancestrales que la han hecho productiva (Hernández, 2009).

En lo que tiene que ver con su forma de vida diferenciada se ha concluido que los grupos campesinos se identifican igualmente con la idea de comunidad entendida como un grupo social que tiene identidades configuradas a partir de relaciones de parentesco, historia de lucha compartida y elementos de cooperación de orden económico, político, cultural y simbólico ${ }^{31}$ (CNMH, 2015)

30 Entendida como el derecho que tienen los pueblos a alimentos sanos, producidos mediante métodos sostenibles y el derecho de ejercer su autoridad para definir sus propios sistemas agrícolas y alimentarios (Ferro, 2013).

31 La forma de vivir, la forma de compartir y las necesidades que tenemos en la misma, como comunidades, vivimos la misma situación y como comunidad estamos para resolverlas juntos. El sentir de todas esas personas que habitamos dentro de la misma población. Más que todas las necesidades, los problemas que combatimos, 
Uno de los avances más significativos en la consagración a nivel constitucional de estos factores sociales y políticos diferenciadores se encuentra en el proyecto de acto legislativo presentado el pasado 5 de abril de $2016^{32}$ al Congreso, que tiene como objetivo modificar el artículo 64 de la Constitución Política de Colombia para introducir en la misma un reconocimiento constitucional a este grupo social, con fundamento en la protección de su forma de vida y particularmente sus relaciones con la tierra. Dicho proyecto de acto legislativo se presenta acogiendo las recomendaciones de organismos internacionales que han realizado estudios de la situación del agro en Colombia y donde se ha determinado que debe mejorarse la normatividad vigente, llenar las lagunas existentes y elaborar un instrumento jurídico sobre los trabajadores rurales con el que se protejan los derechos de los campesinos y trabajadores rurales en general a nivel constitucional ${ }^{33}$.

Dentro de los motivos para promover dicha reforma se expone que la protección constitucional a los campesinos resulta insuficiente, pues su consagración se realizó en clave de su caracterización como fuerza productora, es decir, como agente económico, mas no como un agente social con una identidad y prácticas propias, fundamentándose en lo

nos toca unirnos para crear fortalezas, tener ese arraigo a nuestro territorio, como hemos sido sacados y perdimos ese arraigo a nuestra comunidad, y queremos volver. Hay que profundizar en el tema, no solo echar el cuento. Si nos paramos hace cuarenta años, había unas comunidades muy acentuadas, y vivimos cincuenta años de violencia, primero liberal y conservadora, luego la violencia paramilitar. Bueno, tenemos miles de asentamientos humanos, allá aparece la iglesia, y con el tiempo se van poblando y se convierte en comunidad, pero primero son un asentamiento humano. Por ejemplo, el corregimiento de Córdoba, cincuenta años, donde era selva, sacados de las sabanas de Bolívar y Sucre (CNMH, 2015, p.29). Denominado proyecto de acto legislativo 12 de 2016, por medio del cual se reconoce el derecho a la tierra y a la territorialidad campesina y se adoptan disposiciones sobre la consulta popular. Gaceta No. 126 de 2016 del Congreso de la República.

33 Consejo de Derechos Humanos, Estudio definitivo del Comité Asesor del Consejo de Derechos Humanos sobre la promoción de los derechos de los agricultores y de otras personas que trabajan en las zonas rurales, documento $\mathrm{A} / \mathrm{HRC} / \mathrm{AC} / 8 / 6,23 \mathrm{de}$ enero de 2012. 
afirmado por el informe desarrollo humano de 2011 realizado por el PNUD, en el sentido de que el campesinado no ha sido todavía reconocido socialmente. Para lograr esto, se propone que se modifique el término "trabajador agrario", por considerar que el mismo deja por fuera elementos constitutivos de la identidad campesina.

Se propone, entonces, un reconocimiento del campesinado a través de la investigación por medio de cartografía social, de la identificación de los rasgos que los caracterizan en cuanto a su dependencia de la tierra, arraigo ancestral y cosmovisión, y se concibe este reconocimiento como una forma de reparación frente a las múltiples victimizaciones que ha sufrido $^{34}$. Fundamentan su necesidad de reconocimiento diferenciado en que los campesinos son un grupo social diverso con un proyecto de vida comunitaria o familiar que se centra en actividades para su sustento, específicamente en el aprovechamiento tradicional de la tierra rural, protegiendo el ambiente y los ecosistemas del campo junto con unas costumbres regionales a nivel rural.

Esta iniciativa es un gran avance en el pago de la deuda que el sistema jurídico tiene con la protección de la forma de vida campesina y un punto de partida importante en el camino hacia el reconocimiento de sus derechos territoriales, sociales, políticos y culturales, el cual se encuentra históricamente fundamentado, ya que como mostró a lo largo del presente escrito, las reivindicaciones del movimiento campesino mestizo y sus características diferenciadoras son compartidas con la población indígena y afrocolombiana. 


\section{Bibliografía}

Arboleda, P. B. (2013). La agenda de paz: participación política de las Farc-EP y la justicia transicional en Colombia. Revista Jurídica de la Universidad de Caldas, 10(2).

Bonilla Maldonado, D. E.; Kahn, P. W. y Holguín, M. (2006). La constitución multicultural. Bogotá: Siglo del Hombre Editores, Universidad de los Andes, Facultad de Derecho Pontificia Universidad Javeriana, Instituto Pensar.

Castillo Gómez, L. C. (2005). El estado-nación pluriétnico y multicultural colombiano: la lucha por el territorio en la re imaginación de la nación y la reinvención de la identidad étnica de negros e indígenas (tesis doctoral). Universidad Complutense, Madrid.

Castillo, L. C. (2007). Etnicidad y nación el desafío de la diversidad en Colombia (1a ed.). Cali: Programa Editorial Universidad del Valle.

Centro Nacional de Memoria Histórica (2015). Memorias. Territorio y luchas campesinas Aportes metodológicos para la caracterización del sujeto y el daño colectivo con población campesina en la región caribe desde la perspectiva de memoria histórica (Documento de trabajo). Bogotá: Autor.

Congreso de Colombia. Gaceta del Congreso No. 126 de 2016.

Cunin, E. (2003). Identidades a flor de piel. Lo "negro" entre apariencias y pertenencias: categorías raciales y mestizaje en Cartagena. Bogotá: Instituto Colombiano de Antropología e Historia (Icanh), Universidad de los Andes, Instituto Francés de Estudios Andinos (Ifea) y Observatorio del Caribe Colombiano.

Escobar, C. (1983). Trayectoria de la ANUC. Bogotá: Cinep

Ferro Medina, J. G. y Herrera Arango, J. (2013). Experiencias de organización social del territorio en comunidades campesinas, indígenas y afrodescendientes. En: Territorios campesinos: la experiencia de las Zonas de Reserva Campesina. Universidad Nacional de Colombia (1a ed.). Bogotá: Instituto Colombiano de Desarrollo Rural.

Figueroa, J. A. y Rappaport, J. (2009). Realismo mágico, vallenato y violencia política en el Caribe colombiano (1a ed.). Bogotá: Instituto Colombiano de Antropología e Historia. 
Galvis Parra, J. J. (2010). Historia del fortalecimiento organizativo del consejo regional indígena del cauca (1971-1991) (tesis de pregrado). Pontificia Universidad Javeriana, Bogotá.

Garcia, J. F. (2016). Contexto histórico de los daños a la Anuc. Recuperado de: http://etnoterritorios.org/apc-aa-files/92335f7b3cf47708a7c984a30940 2be7/contexto-histtico-de-los-daos_anuc.pdf

Hernández Navarro, L. y Aurélie Desmarais, A. (2009). Crisis y soberanía alimentaria: vía campesina y el tiempo de una idea. El Cotidiano, 89-95. Recuperado de http://www.redalyc.org/articulo.oa?id = 32515313

Herrera, J. (2016). Daños al territorio y al paisaje campesino de la Anuc. Recuperado de: http://etnoterritorios.org/CentroDocumentacion. $\operatorname{shtml?apc}=\mathrm{x}$ $\mathrm{xx}-1-\& \mathrm{x}=1013$

Jimeno, M. (1998). Juan Gregorio Palechor: tierra, identidad y recreación étnica. Alteridades, 6(11), 96-106.

Laurent, V. (2010, enero-junio). Con bastones de mando o en el tarjetón. Revista Colombia Internacional, (71), 35-61. Doi: http://dx.doi.org/10.7440/ colombiaint71.2010.03

Lemaitre Ripoll, J. (2009). El derecho como conjuro fetichismo legal, violencia y movimientos sociales. Bogotá: Siglo del Hombre Editores, Universidad de Los Andes Facultad de Derecho.

Mosquera Mosquera, J. de D. (2007). La población afrocolombiana: realidad, derechos y organización ( $5^{a}$ ed., actualizada). Bogotá: Sigma Editores, Movimiento Nacional Cimarrón

Múnera Ruiz, L.; Cárdenas, M. y Hernán, D. C. (1998). Bogotá: Universidad Nacional de Colombia, Instituto de Estudios Políticos y Relaciones Internacionales, Centro de Estudios de la Realidad Colombiana.

Peñaranda Supelano, D. R. (2015). Guerra propia, guerra ajena. Conflictos armados y reconstrucción identitaria en los Andes colombianos. El movimiento armado Quintín Lame. Bogotá: CNMH-IEPRI.

Perez, J. M. (2010). Luchas campesinas y reforma agraria. Memorias de un dirigente de la Anuc en la costa caribe (1 a ed.). Bogotá: Puntoaparte Editores. 
Programa de las Naciones Unidas para el Desarrollo (2011). Informe de Desarrollo Humano. Colombia Rural. Recuperado de: http://pnudcolombia.org/ indh2011/

Pulido Londoño, H. A. (2010, julio-diciembre). Bogotá. Violencia y asimetrías étnicas. Multiculturalismo, debate antropológico y etnicidad de los afrocolombianos (1980-1990). Antípoda, Revista de Antropología y Arqueología, (11), 259-289.

Restrepo, E. (2013). Etnización de la negridad: la invención de las "comunidades negras" como grupo étnico en Colombia ( $1^{a}$ ed.). Popayán: Universidad del Cauca, Samava Ediciones.

Reyes, A. (1991). Conflicto y territorio en Colombia. En: El campesinado en Colombia hoy. Diagnóstico y perspectivas. (1 a ed.). Bogotá: Presencia, Pontificia Universidad Javeriana, Facultad de Ciencias Económicas y Administrativas.

Rivera, H. C. y Ferro, J. G. (2016). Daños a la organización. Recuperado de: http://www.etnoterritorios.org/CentroDocumentacion.shtml? $\mathrm{apc}=\mathrm{x}-\mathrm{xx}-1$ $\& \mathrm{x}=1012$

Rojas Guerra, J. M. (2012). Campesinos e indios en el suroccidente colombiano. Cali: Programa Editorial Universidad del Valle.

Sánchez Gutiérrez, E. y Molina Echeverri, H. (2010). Documentos para la historia del movimiento indígena colombiano contemporáneo. Bogotá: Ministerio de Cultura.

Silva Prada, D. F. (2012). La democratización de los espacios regionales y el trabajo político de la organización campesina en Colombia. Polis [En línea], 28. Recuperado de: http://polis.revues.org/1257

Zuleta, E. (1973). La tierra en Colombia. Bogotá: Editorial Oveja Negra. 